\title{
Pressor threshold of muscle metaboreflex is modulated during unloading of carotid baroreceptors in humans
}

\author{
Masashi Ichinose ${ }^{1 *}$, Tomoko Ichinose ${ }^{2}$, Kazuhito Watanabe ${ }^{3}$, Takeshi Nishiyasu ${ }^{3}$ \\ From 15th International Conference on Environmental Ergonomics (ICEE XV) \\ Portsmouth, UK. 28 June - 3 July 2015
}

\begin{abstract}
Introduction
Static and dynamic exercise are accompanied by increases in arterial blood pressure, heart rate and sympathetic nerve activity. It is thought that the activation of the muscle metaboreflex is one of major mechanisms for evoking the pressor responses during heavy intensity exercise [1]. It has been shown that the arterial baroreflex buffers the muscle metaboreflex-mediated pressor responses [2]. However, it is unknown whether the carotid baroreflex modifies muscle metaboreflex function in humans. Therefore, the purpose of this study was to investigate the effects of unloading of carotid baroreceptors on threshold and gain of the muscle metaboreflex in humans.
\end{abstract}

\section{Methods}

Subjects (nine males and one female with a mean age of 23 (2) years, a body weight of 63.2 (3.0) $\mathrm{kg}$, and a height of $171.0(2.8) \mathrm{cm}$.) performed static handgrip exercise at $50 \%$ of maximum voluntary contraction. The contraction was sustained for $15,30,45$ and $60 \mathrm{~s}$, followed by 3 min of circulatory arrest, respectively. It has been demonstrated that in this maneuver, forearm muscular $\mathrm{pH}$ during the ischemia linearly decreases with increasing contraction time [3]. The carotid baroreceptors were unloaded by $0.1 \mathrm{~Hz}$ sinusoidal neck pressure (oscillates from 15 to $50 \mathrm{mmHg}$ ) during the third min of ischemia. We compared cardiovascular responses during the ischemia with and without unloading of the carotid baroreceptors. In addition, we estimated the threshold and gain of the muscle metaboreflex by analyzing the

\footnotetext{
* Correspondence: ichinose@meiji.ac.jp

'Human Integrative Physiology Laboratory, School of Business

Administration, Meiji University, Tokyo, Japan

Full list of author information is available at the end of the article
}

relationship between cardiovascular responses during the third min of ischemia and amount of work during handgrip (i.e., integrated values of handgrip force).

\section{Results}

During unloading of carotid baroreceptors, the muscle metaboreflex thresholds for mean arterial blood pressure (MAP) and for total vascular resistance (TVR) located significantly lower work amount compared to those in control conditions (threshold for MAP: 795 (32) vs. 662 (66), for TVR: 818 (67) vs. 572 (92) kg.s, p < 0.05). The gains of the muscle metaboreflex that were estimated as maximum rate of changes in hemodynamic values to change in work amount were not different between these two conditions (gain for MAP: 4.9 (0.5) vs. 4.4 (0.5) mmHg.kg.s $\mathrm{s}^{-1} .100$, for TVR: $1.3(0.3)$ vs. $\left.1.3(0.2) \mathrm{mmHg} \cdot \mathrm{L}^{-1} \cdot \mathrm{min}^{-1} \cdot \mathrm{kg} \cdot \mathrm{s}^{-1} \cdot 100\right)$.

\section{Discussion}

Our results show that unloading of carotid baroreceptors lowers the pressor threshold of the muscle metaboreflex in humans. This indicates that under normal blood pressure conditions, the carotid baroreflex shifts the threshold to a higher metabolic stimulation level and thus inhibits the muscle metaboreflex mediated pressor response.

\section{Conclusion}

We conclude that the carotid baroreflex modifies the muscle metaboreflex threshold in humans. We suggest that the modulation of the muscle metaboreflex function through carotid baroreflex would contribute to cardiovascular regulations during exercise. 


\section{Authors' details}

${ }^{1}$ Human Integrative Physiology Laboratory, School of Business

Administration, Meiji University, Tokyo, Japan. ${ }^{2}$ Laboratory for Human

Performance Research, Osaka International University, Osaka, Japan. ${ }^{3}$ Institute of Health and Sports Science, University of Tsukuba, Tsukuba, Japan.

Published: 14 September 2015

\section{References}

1. Rowell LB, O'Leary DS: Reflex control of the circulation during exercise: chemoreflex and mechanoreflexes. J Appl Physiol 1990, 69:407-418.

2. Sheriff DD, O'Leary DS, Scher AM, Rowell LB: Baroreflex attenuates pressor response to graded muscle ischemia in exercising dogs. Am J Physiol Heart Circ Physiol 1990, 258:H305-H310.

3. Nishiyasu T, Ueno H, Nishiyasu M, Tan N, Morimoto K, Morimoto A, Deguchi T, Murakami N: Relationship between mean arterial pressure and muscle cell $\mathrm{pH}$ during forearm ischaemia after sustained handgrip. Acta Physiol Scand 1994, 151:143-148.

doi:10.1186/2046-7648-4-S1-A62

Cite this article as: Ichinose et al:: Pressor threshold of muscle metaboreflex is modulated during unloading of carotid baroreceptors in humans. Extreme Physiology \& Medicine 2015 4(Suppl 1):A62.

\section{Submit your next manuscript to BioMed Central} and take full advantage of:

- Convenient online submission

- Thorough peer review

- No space constraints or color figure charges

- Immediate publication on acceptance

- Inclusion in PubMed, CAS, Scopus and Google Scholar

- Research which is freely available for redistribution

Submit your manuscript at www.biomedcentral.com/submit 